\title{
SYNERGISTIC HAEMOLYTIC ACTIVITY AND ITS CORRELATION TO PHOSPHOLIPASE D PRODUCTIVITY BY CORYNEBACTERUIM PSEUDOTUBERCULOSIS EGYPTIAN ISOLATES FROM SHEEP AND BUFFALOES
}

\author{
Selim, S.A. ${ }^{\text {; }}$ Mousa, W.M. ${ }^{\text {; }}$ Mohamed, K.F. ${ }^{2}$; Moussa, I.M. ${ }^{3 *}$ \\ ${ }^{1}$ Biotechnology Center for Veterinary Services and Research (BCVSR), Faculty of Veterinary Medicine, Cairo University; \\ ${ }^{2}$ Department of Microbiology, Faculty of Veterinary Medicine, Cairo University; ${ }^{3}$ Center of Excellence in Biotechnology \\ (CEBER) King Saud University, P. O. 2460 Riyadh King Saudi Arabia.
}

Submitted: February 26, 2011; Returned to authors for corrections: May 09, 2011; Approved: January 16, 2012.

\begin{abstract}
Fourteen isolates of Corynebacteruim pseudotuberculosis of them 7 were isolated from sheep with Caseous Lymphadenitis "biotype 1" and 7 isolated from buffaloes with Oedematous Skin Disease "biotype 2". All isolates were identified by standard microbiological techniques and by polymerase chain reaction targeting, 16S rRNA and phospholipase $D$ genes. Synergistic haemolytic titers of all isolates were assayed by plate technique. The presences of phospholipase $D$ gene in supernatants of all isolates were performed by sodium dodecyl sulfate polyacrylamide gel electrophoresis immunoblot technique by using hyperimmune serum raised in rabbit immunized with recombinant phospholipase $D$ gene antigen. The concentration of phospholipase $D$ gene was assayed by scanning the bound phospholipase $D$ gene with specific antibodies that appeared at $31.5 \mathrm{kDa}$. Results presented that there is no correlation between titer of Synergistic haemolytic activity and the actual phospholipase $D$ genes concentration in culture supernatants. Also results presented that Synergistic haemolytic activity and phospholipase D genes produced by biotype 2 (buffalo isolates) was generally higher than those by biotype 1 (sheep isolates).
\end{abstract}

Key words: Corynebacteruim pseudotuberculosis, Oedematous Skin Disease, Caseous Lymphadenitis, recombinant PLD, Synergistic haemolysis.

\section{INTRODUCTION}

Phospholipase D (PLD) is a potent exotoxin produced by Corynebacteruim pseudotuberculosis of sheep origin $(9,11$, 26) and by buffalo isolates (8). PLD is a secreted exotoxin that possesses sphingomyelinase activity and has been shown to increase vascular permeability $\mathrm{IN}$ vivo $(2,30)$, exhibit synergistic haemolysis ( $\mathrm{SH})$ of sheep blood cells in the presence of products from Rhodococcus equi and reduce the viability of ovine neutrophilis (2). Depending upon the information that PLD is the major virulence factor in $C$. pseudotuberculosis, many significant efforts have been made to produce effective caseous lymphadenitis (CLA) vaccines. The majority of prepared vaccines were derived from PLD-rich culture supernatants, inactivated with formalin to produce toxoid vaccine $(6,20,21,29)$. But field application of these

*Corresponding Author. Mailing address: Center of Excellence in Biotechnology Research, King Saud University, P. O. Box 2460 - Riyadh King Saudi Arabia.; Tel.: 00966560749553 Fax: 00966-14678456.; E-mail: imoussa1@ksu.edu.sa / moussaihab@gmail.com 
toxoid vaccines showed controversy character while Eggleton et al. (7) were satisfactory about protective efficacy of PLD toxoid vaccines. Other researchers reported that toxoid vaccines and inactivated corynebacterial cells (bacterins) provide partial protection (3).

The reason of inadequate toxoid vaccines is still obscure, although Paton et al. (18) attributed this low effective protection to the inappropriate use of the vaccine and reported that although $43 \%$ of the farmers applied commercial CLA vaccines, only $12 \%$ used them correctly. One of the propositions that may help in explanation of the inadequacy of some toxiod vaccines may be attributed to variation in concentration of PLD included in culture supernatants used for preparation of the toxoid vaccine.

Concentration of PLD in culture supernatants is evaluated by indirect methods depending upon its synergistic haemolytic activity. They considered the increase in SH activity is correlated to the concentration of PLD included in culture supernatants, although there is still no definitive evidence that PLD and SH activity are one and the same (6). The fixed optimal amount of antigen in any vaccine is an important factor in preparation of vaccine, this condition cannot be guaranteed in toxoid vaccines in which the PLD antigen is measured by SH activity of culture supernatants.

The correlation between SH activity and the actual concentration of PLD included in culture supernatants has not been previously explored. The present investigation was undertaken to evaluate the correlation between SH activity and the actual concentration of PLD involved in culture supernatants of $C$. pseudotuberculosis obtained from sheep with Caseous Lymphadenitis (CLA) and buffaloes with Oedematous Skin Disease (OSD).

\section{MATERIALS AND METHODS}

\section{Clinical specimens}

Fourteen pus samples were collected aseptically from abscessed lymph nodes of naturally infected sheep $(n=7)$ and buffaloes $(n=7)$ found in two CLA- OSD endemic areas of Egypt. Microbiological examinations, followed by biochemical identification, were used as a gold standard to confirm infection with C. pseudotuberculosis. In brief, bacteriological cultures were made of pus specimens and the resultant $C$. pseudotuberculosis-resembling colonies that stained Grampositive were tested further for biochemical properties (glucose fermentation, urease and catalase) (7, 31). Synergistic haemolysis with Rhodococcus equi ATCC 33701 and inhibition of $\beta$-haemolysis by Staphylococcus aureus ATCC 25923 were also evaluated $(7,31)$.

\section{Bacterial strains and culture condition}

The study was undertaken with 7 isolates recovered from buffaloes infected with OSD and 7 isolates recovered from sheep infected with (CLA). Isolates were cultured initially into brain heart agar supplied with fosfomzein and nalidixic acid (31).

Biotypes were determined by conventional tests as described previously (1) in addition to starch hydrolysis.

\section{Starch agar hydrolysis test}

It is prepared as in welcome to microbugs starch agar medium with some modification. Briefly the differential medium was prepared by suspension of $25 \mathrm{~g}$ of starch powder in $1 \mathrm{~L}$ of purified water, mixed thoroughly and boiled for $1 \mathrm{~min}$ to completely dissolve the powder, then $15 \mathrm{~g}$ of brain heart agar (Oxoid $(\circledR)$ were added, mixed thoroughly, then autoclaved at $121^{\circ} \mathrm{C}$ for $15 \mathrm{~min}$. Isolates were streaked on plates of starch agar and incubated for 48 hours at $37^{\circ} \mathrm{C}$. The surfaces of inoculated media were flooded with Gram iodine. Starch hydrolysis was indicated by the development of a clear zone around the colonies against a dark blue back ground.

DNA isolation: Two different protocols were adapted for extracting DNA from pure bacterial cultures and clinical samples. 
Bacterial cultures: Chromosomal DNA extraction from bacterial strains was carried out according to the standard protocol of Sambrook et al. 22 with some modification .The DNA concentrations was determined spectrophotometrically.

Clinical samples: $100 \mathrm{mg}$ pus was resuspended in $1 \mathrm{ml}$ TE/lysozyme. Samples were incubated for $1 \mathrm{~h}$ at $37{ }^{\circ} \mathrm{C} ; 20 \mu \mathrm{l}$ proteinase $\mathrm{K}$ (20 $\mathrm{mg} \mathrm{ml}^{-1}$; Invitrogen) was added, followed by incubation for $2 \mathrm{~h}$ at $56{ }^{\circ} \mathrm{C}$. Samples were divided into two aliquots of $500 \mu \mathrm{l}$, and $25 \mu 130 \%$ (w/v) sarcosyl was added to each; mixtures were incubated for $20 \mathrm{~min}$ at $65^{\circ} \mathrm{C}$ and then for 5 min at $4{ }^{\circ} \mathrm{C}$. DNA was purified and precipitated as described above.

\section{Primers and PCR conditions}

The oligonucleotide primers used in this study were designed to detect $16 \mathrm{~S}$ rRNA and PLD genes of $C$. pseudotuberculosis. Both of them were obtained from previously published work $(4,13,17)$. The oligonucleotide primers specific for 16S rRNA; 16S-F 5' ACC GCA CTT TAG TGT GTG TG3' and 16S-R 5' TCT CTA CGC CGA TCT TGT AT 3' could amplify 816 base pair fragments. The oligonucleotide primers specific for PLD genes of $C$. pseudotuberculosis; PLD F5': CGG CCC GGG ATT ATG GCG ATC ATG CTT C3' and PLD R5': CGC AAG CTT TCA CCA CGG GTT ATC CGC T 3' could amplify 930 base pair fragments. The PCR reactions will carry out according to Cetinkaya et al.,4.

\section{Anti-recombinant phospholipase D hyperimmune sera}

A highly specific rabbit hyperimmune serum was prepared by inoculation of rabbits with recombinant PLD (rPLD) antigen prepared and provided from Biotechnology Center of Veterinary Services and Researches (BCVSR) Cairo University (8). Three Boscat rabbits weighing $2.5 \mathrm{Kg}$ were inoculated subcutaneously with $1 \mathrm{ml}$ dose containing $25 \mu \mathrm{g}$ rPLD protein mixed with complete Freund's adjuvant (Sigma) followed by 2 doses of $25 \mu \mathrm{g}$ rPLD mixed with incomplete Freund's adjuvant
(Sigma) at weekly intervals. One week post last dose antibodies were assayed by ELISA (23) using rPLD protein as a coating antigen. Titers were expressed as the reciprocal of the dilution which gave an OD three fold above the OD of preimmune serum analysed on the same plate. Titers obtained from immunized rabbits were more than 128 and sera were pooled, aliquoted and stored in $-20^{\circ} \mathrm{C}$.

\section{Selective media for obtaining maximum yield of PLD}

C. pseudotuberculosis loses its power of PLD production under laboratory storage conditions and it needs reactivation process during subculturing from the stock cultures. To guarantee the maximum yield of PLD produced by stock cultures of Corynebacteria, we used the 2 stages media recommended by Soheir (24) that activate stock culture to produce maximum amounts of PLD.

The first stage of cultivation was performed by inoculation of bacteria into cooked meat medium (Oxoid () ) and incubated at $37^{\circ} \mathrm{C}$ for 24 hours, then the whole constituents of incubated culture were transferred into flasks that contain brain heart broth (Oxoid $($ ) ) supplied with $0.1 \%$ v/v Tween 80 and 3\% glucose in a percent of 1 part cooked meat medium to 3 parts of $\mathrm{BH}$ broth. Mixed media were incubated in shaker incubator for 48 hours at $37^{\circ} \mathrm{C}$.

\section{Titration of synergistic haemolytic activity of culture filtrates}

Synergistic haemolytic ( $\mathrm{SH}$ ) activity of culture filtrates (CF) that rich in PLD was titrated by plate method according to Tachedjian et al. (27).

Briefly in 96 round button plates $200 \mu$ of filtered culture supernatant were dispensed in the first well and $50 \mu \mathrm{l}$ of sterile PBS to subsequent wells, taken $150 \mu \mathrm{l}$ from the first well were mixed with the second well and so on in subsequent wells. To each well defibrinated sheep blood and filtered Rhodococcus equi culture supernatants were added to all wells in a final concentration of $1.5 \%$ and $13.5 \%$, respectively. Plates were 
incubated overnight at $37^{\circ} \mathrm{C}$ and titers were red as the last well to exhibit complete haemolysis.

\section{Electrophoresis and immunoblotting}

Total proteins in each culture filtrate were measured by Lowry et al. (12), then concentrated to $1 / 20$ of the original volume ( $1 \mathrm{ml}$ to $50 \mu \mathrm{l})$ by using the dry vacuum concentration ( Speedvac System-Savant \# SS11).

Each concentration sample was treated with reducing buffer (Tris $91 \mathrm{~g}$, SDS 1\%, distilled water $500 \mathrm{ml}$ ) in the ratio of $1: 1$; the treated samples were immersed in a boiling water bath for 2 minutes to ensure protein denaturation. Electrophoresis was performed (10). Briefly $10 \mu \mathrm{l}$ of each treated concentrate were loaded into each lane and electrophoresis was done for 4 to 6 hours at 100 volt. Gels were fixed overnight in 50\% ethanol and 5\% glacial acetic acid, followed by staining with $0.25 \%$ commasie dissolved in destaining solution (45\% methanol, 5\% glacial acetic acid, $50 \%$ distilled water) for 1 hour, followed by destaining of the gels till the background become completely clear. Proteins in some unstained gels were electrotransferred to nitrocellulose membranes (28). Membranes that were blocked with blocking buffer $(5 \%$ bovine serum albumin in $0.3 \%$ PBS-Tween, $\mathrm{pH}$ 7.2) for 2 hours were washed in washing buffer and spliced into strips. In this investigation, we used highly purified recombinant PLD produced in BCVRS by Ghoneim et al. (8). The rPLD antigen was used for preparation of highly specific hyperimmune serum against PLD. This rabbit hyperimmune serum was used for binding to specific electrophorotic bands resulted in SDS-PAGE immunoblot technique

The strips were exposed to diluted rabbit hyperimmune serum (1:50) and incubated for 1 hour at $25^{\circ} \mathrm{C}$. The strips were washed 3 times ( 5 minutes each) in washing buffer and then were exposed to goat antirabbit IgG peroxidase conjugate (Sigma) diluted 1:1000. Bound antibody was visualized by use of 4-chloro-1-naphthol $/ \mathrm{H}_{2} \mathrm{O}_{2}(0.5 \mathrm{mg} / \mathrm{ml} / 0.15 \%$ in PBS with $17 \%$ methanol) as substrate. Inoculation with substrate was in dark at $25^{\circ} \mathrm{C}$ for 45 minutes.

\section{Analysis of immunoblotted bands}

PLD protein in bound bands was assayed by Gel-Proprogram (USA).

\section{RESULTS}

\section{Characteristics of strains}

The pattern of diagnostic tests for 14 strains revealed 7 strains of C. pseudotuberculosis of sheep origin and 7 strains of buffalo origin. Results in Table 1 revealed that the two biotypes could only be distinguished by nitrate reduction test and starch hydrolysis. C. pseudotuberculosis biotype 2 is nitrate positive and could hydrolyse starch. Moreover, it had been noticed that the two major criteria which are nitrate reduction and starch hydrolysis can distinguish these organisms as shown in Figure 1.

Table 1: Diagnostic reaction of C. pseudotuberculosis of sheep origin and buffalo origin

\begin{tabular}{lcc}
\hline \multicolumn{1}{c}{ Test } & Sheep isolates & Buffalo isolates \\
\hline Sugar fermentation & & \\
$\quad$ - Glucose & $7 / 7$ & $7 / 7$ \\
- Maltose & $7 / 7$ & $7 / 7$ \\
- Fructose & $7 / 7$ & $7 / 7$ \\
- Sucrose & $0 / 7$ & $0 / 7$ \\
Starch hydrolysis & $0 / 7$ & $7 / 7$ \\
Trehalose & $0 / 7$ & $0 / 7$ \\
Urease production & $7 / 7$ & $7 / 7$ \\
Nitrate & $0 / 7$ & $7 / 7$ \\
SH & $7 / 7$ & $7 / 7$ \\
16 rRNA & $7 / 7$ & $7 / 7$ \\
pld gene & $7 / 7$ & $7 / 7$ \\
\hline
\end{tabular}




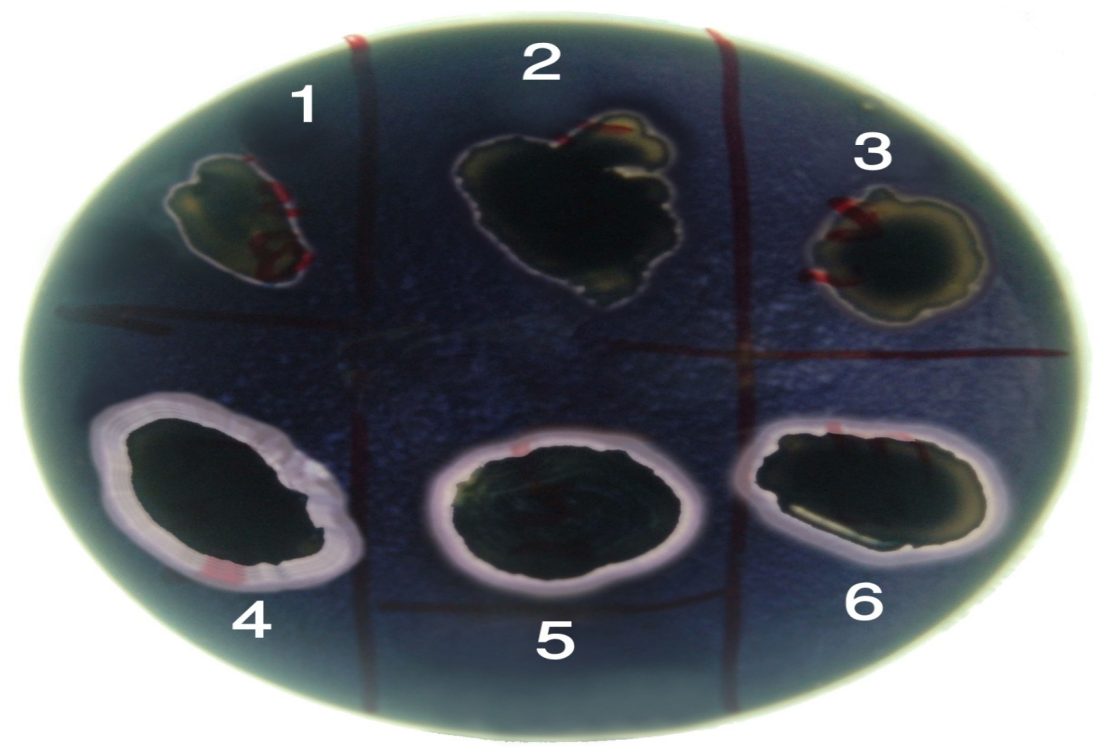

Figure 1: Starch hydrolysis plate showing clear zone of hydrolysis around colonies of C. pseudotuberculosis of buffalo origin Number. $(4,5,6)$ and sheep isolates Number $(1,2,3)$ showing no hydrolysis.

\section{Characterization of the isolates using PCR}

Amplification of $816 \mathrm{bp}$ fragments specific for $16 \mathrm{~S}$ rRNA of C. pseudotuberculosis were observed with all strains collected from sheep and buffaloes as shown in Figure 2. Moreover, amplification of 910 bp fragments specific for PLD gene were also observed with all sheep and buffaloes strains of C. pseudotuberculosis as shown in Figure 3.

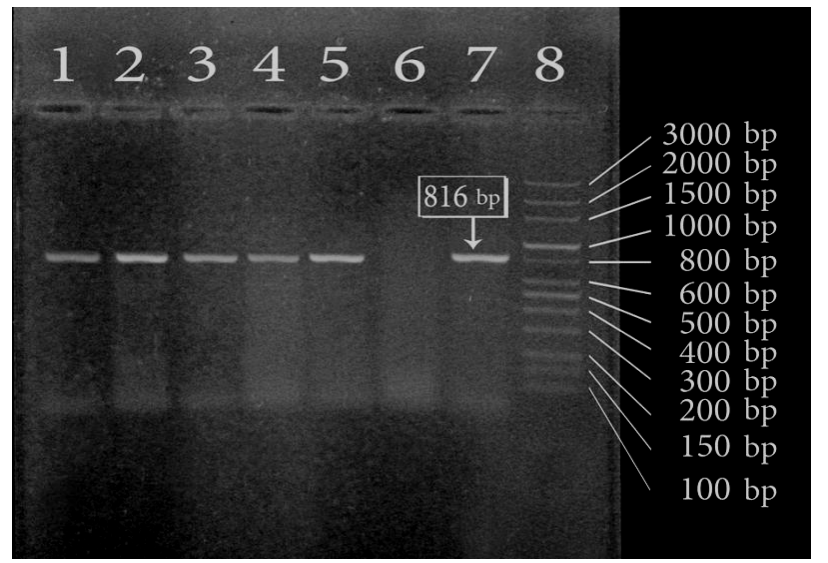

Figure 2: Agarose gel electrophoresis showing amplification of $816 \mathrm{bp}$ fragments specific for $16 \mathrm{~S}$ rRNA of $C$. pseudotuberculosis. While lane 6 showing negative control.

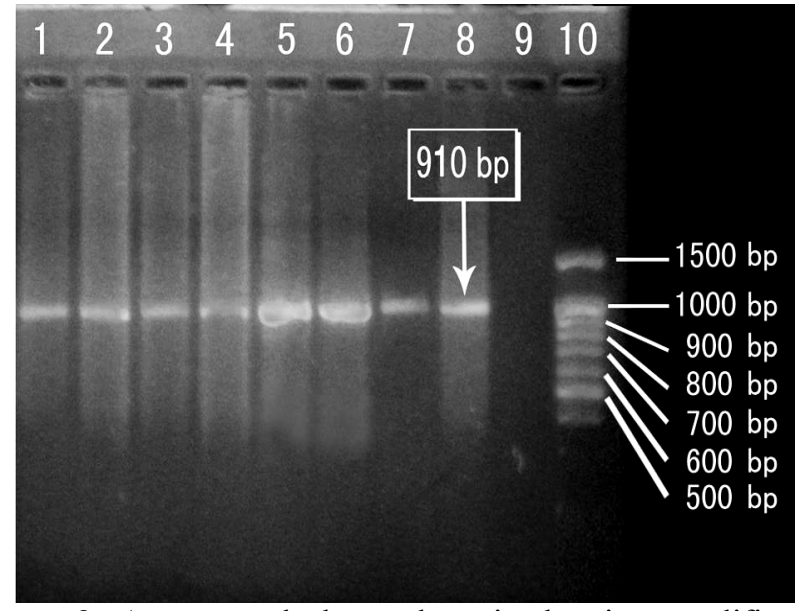

Figure 3: Agarose gel electrophoresis showing amplification of 910 bp bands specific for PLD gene from 4 sheep isolates no. $(1,2,3,4)$ and 4 buffalo isolates No. $(5,6,7,8)$ of $C$. pseudotuberculosis. Lane 9 negative control.

\section{Maximum yield of PLD produced by isolates of $C$. pseudotuberculosis}

All isolates revealed $\mathrm{SH}$ activity by streaking on $\mathrm{BH}$ agar media and all isolates revealed synergistic haemolytic zones around streaked colonies with varying zone of haemolytic 
reaction, but all buffalo isolates showed the wider zones of haemolytic activity of $C$. pseudotuberculosis and the $\mathrm{SH}$ activity haemolysis if compared with sheep isolates. The titers of of both sheep and buffalo isolates are shown in Table 2 .

Table 2: Synergistic haemolytic activity of C. pseudotuberculosis of sheep and buffalo isolates measured by haemolysis zone diameter

\begin{tabular}{|c|c|c|c|c|}
\hline Origin of isolates & No. of isolate & Haemolytic zone & Haemolytic titer & Concentration of PLD in $\mu \mathrm{g} / \mathrm{ml}$ \\
\hline \multirow{7}{*}{ Sheep } & 1 & ++++ & $(1.33)^{7}$ & 18.30 \\
\hline & 2 & ++++ & $(1.33)^{7}$ & 9.32 \\
\hline & 3 & ++ & $(1.33)^{4}$ & 13.40 \\
\hline & 4 & +++ & $(1.33)^{3}$ & 19.40 \\
\hline & 5 & ++ & $(1.33)^{6}$ & 15.20 \\
\hline & 6 & ++ & $(1.33)^{5}$ & 15.90 \\
\hline & 7 & ++ & $(1.33)^{3}$ & 16.20 \\
\hline \multirow{7}{*}{ Buffalo } & 1 & ++++ & $(1.33)^{6}$ & 21.20 \\
\hline & 2 & +++++ & $(1.33)^{5}$ & 19.50 \\
\hline & 3 & +++++ & $(1.33)^{7}$ & 23.90 \\
\hline & 4 & ++++ & $(1.33)^{7}$ & 23.10 \\
\hline & 5 & ++++ & $(1.33)^{7}$ & 18.20 \\
\hline & 6 & +++ & $(1.33)^{4}$ & 19.1 \\
\hline & 7 & ++++ & $(1.33)^{6}$ & 21.20 \\
\hline Haemolytic zone diameter: & $\begin{array}{l}\text { very strong haem } \\
\text { strong haemolysis } \\
\text { oderate haemolysi } \\
\text { k haemolysis } \\
\text { veak haemolysis }\end{array}$ & & & \\
\hline
\end{tabular}

Detection of PLD concentration in culture filtrates of $C$. pseudotuberculosis of sheep and buffalo origin by SDS-PAGE and immunoblot technique

Results in Table 2 show that buffalo isolates produced PLD in concentration range from $18.2 \mu \mathrm{g} / \mathrm{ml}$ up to $23.9 \mu \mathrm{g} / \mathrm{ml}$, while sheep isolates produced PLD in amounts ranged from $9.32 \mu \mathrm{g} / \mathrm{ml}$ up to $19.4 \mu \mathrm{g} / \mathrm{ml}$. It can be observed that the highest concentration of PLD $(19.4 \mu \mathrm{g} / \mathrm{ml})$ was produced by sheep strain showing the least titer of SH activity $(1.33)^{3}$. Also in buffalo isolates, it can noticed that strain No. 6 with haemolytic titre of $(1.33)^{4}$ produced PLD in concentration of $19.1 \mu \mathrm{g} / \mathrm{ml}$ in comparison to strain No. 5 which produced higher titer of SH activity $(1.33)^{7}$ but lower PLD productivity $(18.2 \mu \mathrm{g} / \mathrm{ml})$. Also it can be observed that all isolates that revealed the same titer of $\mathrm{SH}$ activity $(1.33)^{7}$ produced variable amounts of PLD $23.9 \mu \mathrm{g} / \mathrm{ml}, 23.1 \mu \mathrm{g} / \mathrm{ml}$ and $18.1 \mu \mathrm{g} / \mathrm{ml}$ from buffalo isolates No 3, 4, 5, respectively as shown in Table 2.

\section{DISCUSSION}

To assess the $\mathrm{SH}$ of the two biotypes of $C$. pseudotuberculosis and its correlation to the actual concentration of PLD in the culture supernatants, 7 isolates (biotype 1) were collected from sheep showing clinical symptom of CLA and 7 isolates (biotype 2) were collected from buffaloes diseased with OSD. During our investigation about characterization of $C$. pseudotuberculosis of sheep origin (biotype 1) and of buffalo origin (biotype 2), we noticed that, during investigation of $\mathrm{SH}$ activity of both biotypes, the stock culture of Corynebacteria revealed lower $\mathrm{SH}$ activity if compared with recently isolated strains and the extent of decrease that is reversibly related to the period of storage of the isolates which may be attributed to the decrease of PLD production by stock cultures. Moreover, many commercial toxoid vaccines depend upon measuring the $\mathrm{SH}$ activity as indicator for the concentration of PLD secreted into culture supernatants, which needs accurate evaluation of the correlation between SH activity and the indeed concentration of PLD included in supernatants used for preparation of toxoid vaccines. Purification of PLD to homogeneity is a necessary prerequisite to molecular investigation of the enzyme and each extractivity to it including it's SH activity. Purification to near homogeneity has been reported, but it was a method that yields small amounts of enzymes. We need a purification method that 
would allow us to process large volumes of culture supernatant fluid and yield nearly homogenous PLD (6).

All buffalo isolates showed higher $\mathrm{SH}$ activity if compared with sheep isolates (biotype 1) as shown in Table 2. It can be collectively observed that buffalo isolates are more potent in SH activity if compared with biotype 2 (sheep isolates). The reason is not clear but it can be proposed that biotype 2 (buffalo isolates) may produce other hemolytic factors beside PLD that increase the extent of SH activity.

The resulting correlation between the extent of SH activity and actual contents of PLD in supernatants of biotype 1 and biotype 2 isolates is shown in Table 2 . It can be noticed that sheep isolate (No.1) had strong SH activity titer and produced high yield of PLD in culture f supernatants, while isolate (No. 2) having the same high titer of $\mathrm{SH}$ but produced half the amount produced by isolate No. (1). at the same time, strain No. (6) showing less SH titer and produced high concentration of PLD in culture supernatants. The same poor correlation between SH activity and actual amounts of PLD in culture supernatants is observed in strains of biotype 2 (buffalo isolates). Isolate (No. 1) having the least titer of $\mathrm{SH}$ activity and produced PLD in large amounts. Moreover, biotype 2 isolates No. 3, 4, 5 had the highest SH titer, but they produced variable amounts of PLD enzyme in culture supernatants 23.9, $23.1,18.2 \mu \mathrm{g} / \mathrm{ml}$, respectively. The obtained results indicate a poor correlation between SH activity of C. pseudotuberculosis isolate and production of PLD enzyme in culture supernatants. Poor correlation was also reported by previous investigation, Muckle and Gyles, $(14,15)$ reported a poor correlation between PLD enzyme contents in supernatants of $C$. pseudotuberculosis measured by radiometric assay. Egen et al. (6) reported that isolates having 3 fold variations in PLD concentration measured by radiometric assay produced nearly identical areas of haemolysis on Rhodococus blood agar plates.

The explanation of the reason of poor correlation between SH activity and the actual contents of PLD in supernatants of C. pseudotuberculosis still unexplained. Egen et al. (6) reported that there is still no definitive evidence that PLD and
SH activity are one. The SH activity can be used as a predictive assay for the production of PLD by $C$. pseudotuberculosis, but it is inadequate technique to detect the actual concentration of PLD in culture supernatants which can be achieved by SDS-PAGE and immunoblotting technique using highly specific anti-PLD antibodies to maintain a proper amount of PLD antigen in each dose of toxoid vaccine.

\section{ACKNOWLEDGEMENTS}

" This work was supported by the National Plane for Science and Technology Program, Vice Rectorate for Graduate Studies and Scientific Research, King Saud University, 10AGR1316-2".

\section{REFERENCES}

1. Barakat, A.A.; Selim, S.A.; Atef, A.; Saber, M.S.; Nafie, E.K; Elebeedy, A.A. (1984). Two serotypes of Corynebacterium pseudotuberculosis isolated from different animal species. Rev. Sci. Tech. Off. Int. Epiz. 3(1), 151-168.

2. Batey, R.G. (1986). Pathogenesis of caseous lymphadenitis in sheep and goats. Aust. Vet. J. 63, 269-272.

3. Brogden, K.A.; Glenn, J.S; East, N; Audibert, F.A. (1996). Corynebacterium pseudotuberculosis bacterin with muramyl dipeptide induces antibody titers, increases the time of onset, and decreases naturally occurring external abscesses in sheep \& goats. Small Rumin. Res. 19, 161-168.

4. Cetinkaya, B.; Karahan, M.; Atil, E.; Kalin, R.; De Baere, T. ; Vaneechoutte, M. (2002). Identification of Corynebacterium pseudotuberculosis isolates from sheep and goats by PCR. Vet. Microbiol. 88, 75-83.

5. Dercksen, D. P.; Brinkhof, J. M. A.; Dekker-Nooren, T.; van Maanen, K.; Bode, C. F.; Baird, G. ; Kamp, E. M. (2000). A comparison of four serological tests for the diagnosis of caseous lymphadenitis in sheep and goats. Vet. Microbiol. 75, 167-175.

6. Egen, N.B.; Cuevas, W.A.; McNamara, P.J.; Sammons, D.W.; Humphrey, R; Songer, J.G. (1989). Purification of PLD of Corynebacterium pseudotuberculosis by recycling isoelectric focussing. Am. J. Vet. Res. 50, 1319-1322.

7. Eggleton, D.G.; Doidge, C.V.; Middleton, H.D; Mint, D.W. (1991). Immunization against ovine caseous lymphadenitis: Efficacy of monocomponent $C$. pseudotuberculosis toxoid vaccine and combined 
clostridial corynebacterium vaccines. Aust. Vet. J. 68(10),320-321.

8. Ghoneim, M.A.; Mousa, A.W.; Ibrahim, A.K.; Amin, A.S; Khafagi, A; Selim, S.A. (2001). Role of Hippobosca eqiuna as a transmitter of $C$. pseudotuberculosis among buffaloes as revealed by PCR and dot blot hybridization. J. Egypt Vet. Med. Ass. 61, 165-176.

9. Hodgson, A.L.; Bird, P; Nisbet, I.T. (1990). Cloning, nucleotide sequence, and expression in Escherichia coli of the phospholipase D gen from C. pseudotuberculosis. J. Bacteriol. 172(3),1256-12561.

10. Laemmli, U.K. (1970). Cleavage of structural proteins during the assembly of the head of bacteriophage T4. Nature. 227(259), 680-685.

11. Lipsky, B.A.; Goldberger, A.C.; Tompkins, L.S. and Plorde, J.J. (1982). Infections caused by non-diphtheria Corynebacteria. Rev. Infect. Dis. 4(6), 1220-1235.

12. Lowry, O.H,.; Rosenbrough, N.J.; Farr, A.l. and Randali, R.J. (1951).

13. Protein measurement with Folin-phenol reagent. J. Biol. Chem. 193, 265-275.

14. McNamara, P. J.; Bradley, G. A. ;Songer, J. G. (1994). Targeted mutagenesis of the phospholipase D gene results in decreased virulence of Corynebacterium pseudotuberculosis. Mol. Microbiol. 12,921-930.

15. Muckle, C.A; Gyles, C.L. (1983). Relation of lipid content and exotoxin production to virulence of C. pseudotuberculosis in mice. Am. J. Vet. Res. 44 (6), 1149- 1153.

16. Muckle, C.A; Gyles, C.L. (1986). Exotic activities of C. pseudotuberculosis. Current Microbiology, 13:57-60.

17. Murray, P.R.; Baron, E.J.; Pfaller, M.A.; Tenover, F.C; Yolken, R.H. (eds.) (1999). Manual of Clinical Microbiology, $7^{\text {th }}$ ed., ASM Press, Washington, DC, USA.

18. Pacheco, L.G.C.; Pena, R.R.; Castro, T.L.P.; Dorella, F. A.; Bahia, R. C.; Carminati, R.; Frota, M.N.L.; Oliveira, S.C.; Meyer, R.; Alves, F.S.F.; Miyoshi, A; Azevedo, V. (2007). Multiplex PCR assay for identification of Corynebacterium pseudotuberculosis from pure cultures and for rapid detection of this pathogen in clinical samples. J. Med. Microbiol. 56(5), 480-486.

19. Paton, M.W.; Sutherland, S.S; Rose, I.R.; Hart, R.A.; Mercy, A.R; Ellis, T.M. (1995). The speed of Corynebacterium pseudotuberculosis infection to vaccinated and unvaccinated sheep. Aust. Vet. J. 72(7), 266269.

20. Paton, M.W.; Walker, S.B.; Rose, LR; Watt, G.F. (2003). Prevalence of caseous lymphadenitis and usage of caseous lymphadenitis vaccines in sheep flocks. Aust. Vet. J. 81, 91-95.

21. Piontkowski, M.D.; Micheal D.M; Shivers, D.W. (1998). Evaluation of a commercially available vaccine against Corynebacterium pseudotuberculosis for use in sheep. J. Am. Vet. Med. Assoc. 212 (11), 1765-1768.

22. Sambrook, J.; Fritsch, E. F. ; Maniatis, T. (1989). Molecular Cloning: a Laboratory Manual, 2nd edn. Cold Spring Harbor, NY: Cold Spring Harbor Laboratory.

23. Simmons, C.P.; Dunstan, S.J.; Tachedjian, M.; Krywult, J.; Hodgson, A.L; Strugnell, R.A. (1998). Vaccine potential of attenuated mutants of C. pseudotuberculosis in sheep. Infect Immun. 66(2), 474- 479.

24. Soheir, M.F. S. (2006). Characterization of secretory proteins that secreted from Corynebacterium pseudotuberculosis. Giza, Egypt, 80p (Ph. D. Thesis. Bacteriology, Fac. Vet. Med., Cairo Univ.).

25. Smibert, R. M.; Krieg, N. R. (1994). Phenotypic characterization. In Methods for General and Molecular Bacteriology, pp. 607-654. Edited by P. Gerhardt, R. G. E. Murray, W. A. Wood \& N. R. Krieg. Washington, DC: American Society for Microbiology.

26. Tashjian, J.J; Campbell, S.G. (1983). Interaction between caprine macrophages and C. pseudotuberculosis: an electron microscopic study. Am. J. Vet. Res. 44(4), 690-693.

27. Tachedjian, M.; Krywult, L.; Moore, R.J; Hodgson, A.L. (1995). Caseous lymphadenitis vaccine development:site-specific inactivation of the C. pseudotuberculosis phospholipase D gene. Vaccine 13: 17851792.

28. Towbin, H.; Stachelin, T; Gordon, J. (1979). Electrophoretic transfer of proteins from polyacrylamide gels to nitrocellulose sheets. Procedures and some applications. Proc. Nati. Acad. Sci. USA, 76, 4350- 4354.

29. Williamson, L.H. (2001). Caseous lymphadenitis in small ruminates.Vet. Clin. North. Am. Food. Anim. Pract. 17 (2), 359-371.

30. Yozwiak, M.L; Songer, J.G. (1993). Effect of Corynebacterium pseudotuberculosis phospholipase D on viability and chemotactic responses of ovine neutrophils.

Am. J. Vet. Res. 53, 417-431.

31. Zhao, H.K.; Hiramune, T.; Kikuchi, N.; Yanagawa, R.; Ito, S.; Hatta, T.; Serikawa, S; Oe, Y. (1991). Selective medium containing fosfomycin, nalidixic acid and culture supernatant of Rhodococcus equi for isolation of Corynebacterium pseudotuberculosis. J.Vet. Med. Series B. (10), 743748 . 